\title{
Socioeconomic and geographic determinants of survival of patients with digestive cancer in France
}

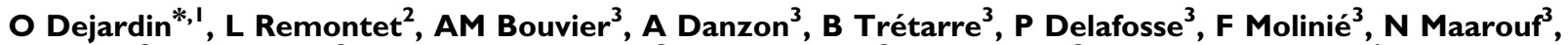 \\ M Velten ${ }^{3}$, EA Sauleau ${ }^{3}$, N Bourdon-Raverdy ${ }^{3}$, P Grosclaude ${ }^{3}$, S Boutreux ${ }^{3}$, G De Pouvourville ${ }^{4}$ and G Launoy ${ }^{1,3}$ \\ 'Cancers \& Populations' ERI 3 INSERM; Faculty of Medicine, Avenue de la Côte de Nacre 14032 Caen Cedex, France; '2Biostatistic Analyses Unit of \\ 'Hospices Civils de Lyon' (HCL), Lyon, France; ${ }^{3}$ French Network of Cancer Registries (FRANCIM), Toulouse, France; ${ }^{4}$ Centre for Research on Medicine, \\ Science, Health and Society (CERMES/INSERM U750), Villejuif, France
}

\begin{abstract}
Using a multilevel Cox model, the association between socioeconomic and geographical aggregate variables and survival was investigated in 81 268 patients with digestive tract cancer diagnosed in the years 1980-1997 and registered in 12 registries in the French Network of Cancer Registries. This association differed according to cancer site: it was clear for colon (relative risk $(R R)=1.10(1.04-1.16), 1.10(1.04-1.16)$ and $1.14(1.05-1.23)$, respectively, for distances to nearest reference cancer care centre between 10 and 30, 30 and 50 and more than $90 \mathrm{~km}$, in comparison with distance of less than $10 \mathrm{~km} ; P$-trend $=0.003)$ and rectal cancer $(R R=1.09(1.03-1.15), R R=1.08(1.02-1.14)$ and $R R=1.12(1.05-1.19)$, respectively, for distances between 10 and $30 \mathrm{~km}, 30$ and $50 \mathrm{~km}$ and 50 and $70 \mathrm{~km}, P$-trend $=0.024)(n=28010$ and $n=18080$, respectively) but was not significant for gall bladder and biliary tract cancer $(n=2893)$ or small intestine cancer $(n=1038)$. Even though the influence of socioeconomic status on prognosis is modest compared to clinical prognostic factors such as histology or stage at diagnosis, socioeconomic deprivation and distance to nearest cancer centre need to be considered as potential survival predictors in digestive tract cancer.
\end{abstract}

British Journal of Cancer (2006) 95, 944-949. doi: I0.1038/sj.bjc.6603335 www.bjcancer.com

Published online 12 September 2006

(c) 2006 Cancer Research UK

Keywords: digestive cancer; road distance; deprivation; distance; multilevel Cox model

The incidence of digestive cancers is still increasing, mainly due to colorectal cancer trends (Parkin et al, 2002), and retains a poor prognosis, as reported by the European Cancer Registries (EUROCARE) study (Berrino et al, 2003). This study found a large range of digestive cancer survival within Europe, while a survival difference in colorectal cancer between Europe and the USA has also been reported (Ciccolallo et al, 2005). To explain such inter-country differences, besides the important effect of stage at diagnosis and surgery, the influence of health system organisation and social determinants needs to be further investigated.

The 5-year relative survival of the 60000 cases of digestive cancer each year in France (Remontet et al, 2003) is reasonably high compared to the European mean. Nevertheless, a few French studies of colorectal cancer from a single cancer registry (Launoy et al, 1992; Desoubeaux et al, 1997) have suggested social inequalities in survival, underprivileged patients having poorer prognosis than more affluent patients. We recently suggested that access to specialised care was strongly associated with road distance to the nearest specialised centre especially for women and elderly patients (Dejardin et al, 2005). Recent research in different health-care systems also suggests a relationship between surgical

*Correspondence: Dr O Dejardin; olivier.dejardin@unicaen.fr Received 17 May 2006; revised 26 July 2006; accepted 26 July 2006; published online 12 September 2006 volume and survival (Kee et al, 1999; Shrag et al, 2000; Platell et al, 2003). Geographical access to reference centres is therefore relevant to the study of social inequalities in cancer survival.

This study, based on data on all digestive cancers registered by the French Network of Cancer Registries (FRANCIM) between 1980 and 1997 in France, investigates the influence of the socioeconomic and geographical environment on survival of affected patients.

\section{MATERIALS AND METHODS}

\section{Population and data}

The study population comprised 81268 patients with digestive tract cancer registered between 1 January 1980 and 31 December 1997 in 12 cancer registries (Calvados, Côte d'Or, Doubs, Hérault, Isère, Loire-Atlantique, Manche, Bas-Rhin, Haut-Rhin, Saône et Loire, Somme and Tarn), all belonging to the French Network of Cancer Registries (FRANCIM); as such, their exhaustiveness and data quality are regularly checked by the French Institute of Health and Medical Research (INSERM) and the International Agency for Research on Cancer (IARC). General characteristics of the study population, representing $14.4 \%$ of the French population $(n=8$ 441366 ), are detailed in Table 1.

Survival was defined as the interval in months between diagnosis and last information on vital status. Two types of variable were used in the study, individual and aggregate. 
Table I Digestive cancer diagnosed between 1980 and 1997 in 12 French Communes

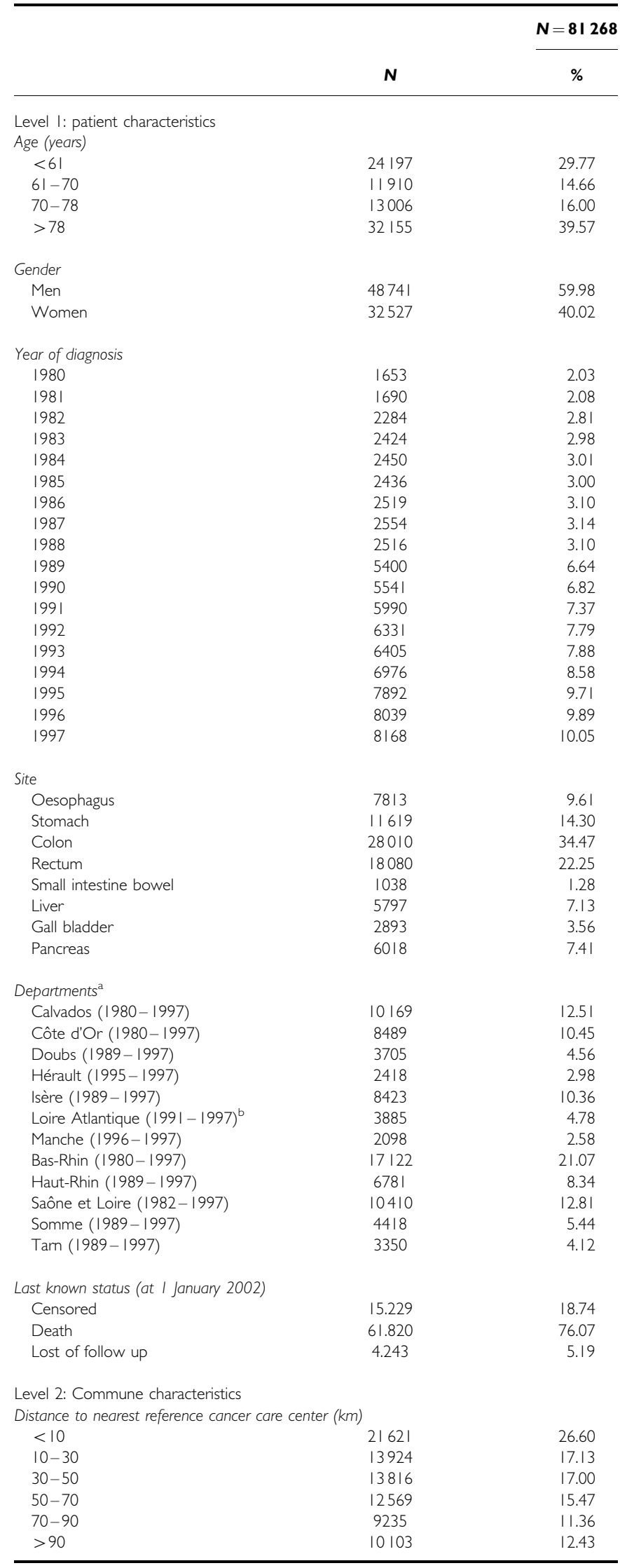

${ }^{a}$ Period contributions are shown in brackets. ${ }^{b}$ Colorectal cancer only.
Level-1 individual variables: data on age, gender, cancer site and Communes (the smallest administrative district in France under the government of a mayor and a municipal council =town/ village) of residence were individually known for all patients and thus considered as individual variables. Cancer site was classified according to ICDO third edition: oesophagus C15-C15.9, stomach C16-C16.9, small intestine $\mathrm{C} 17-\mathrm{C} 17.9$, colon $\mathrm{C} 18-\mathrm{C} 18.9$, rectum (including rectosigmoid junction) C19.9-C21.8, liver C22-C22.1, gall bladder and biliary tract C23.9-C24.9 and pancreas C25-C25.9.

Level-2 aggregate variables: to compensate for the lack of individual information on socioeconomic status, each patient was attributed the socioeconomic characteristics of his neighbourhood (Commune level) using French Census data provided by the INSEE (1999) - National Institute for Statistics and Economic Studies, that is, proportion of people who did not complete secondary education to age 15 , mean taxable income, unemployment rate, proportion of housing without bath or shower, manual worker proportion. Mean taxable income (2003) of each Commune was obtained from the 'Direction Générale des Impôts', the tax department.

French public health authorities have defined reference care centres as centres capable of providing care management of serious pathologies with bad prognosis as well as rare pathologies. In our study, the reference care centres are mainly composed of a university hospital and a specialised cancer centre. Road distance to nearest cancer reference care centre (always located in regional capitals) was calculated using MAPINFO 6.5 (MapInfo corporation) and CHRONOMAP (Magellan engineering). Road database (IGN route 500) of the National Geographic Institute (IGN) included $500000 \mathrm{~km}$ of road. These variables were also considered as level-2 variables.

The population study was distributed within 5416 of the 6289 Communes of the 12 French counties (86.11\%). The mean Commune population was 1342.1 (range $270343-6$ ). The mean number of cases per Commune was 15.00.

\section{Analysis}

A multilevel Cox proportional hazards model was used to take into consideration the hierarchical data structure (Goldstein, 1995). Level 1 included patient characteristics (age, sex and year of diagnosis), level 2 was composed of the Commune's social indicator. All models were adjusted on department of residence (level 3).

Iterative general least square (IGLS) (Poisson first order marginal quasi likelihood (MQL)) was used to estimate the model. For each cancer site, we investigated the influence of each of six socioeconomic level-2 variables after adjustment on age, gender, year at diagnosis and department of residence in eight separate models. The influence of social variables on survival was investigated using linear trend for categorised variables.

Mlwin 2.01 (multilevel model project, London Institute of Education) with survival macro was used to perform the multilevel Cox model.

\section{RESULTS}

Table 2 shows the influence of socioeconomic and geographical environment on survival for patients with digestive tract cancer. The association between socioeconomic and geographical aggregate variables and survival differed by cancer site. This association was clear for colon and rectal cancer $(n=28010$ and $n=18080$, respectively) but not for gall bladder and biliary tract $(n=2893)$ or small intestine $(n=1038)$ cancers. For oesophageal, stomach, liver and pancreatic cancers, prognosis was associated with only one or two socioeconomic or geographic variables. Each of the socioeconomic aggregate variables was associated with at least one cancer site, the most frequently with distance to the nearest cancer reference care centre (hereafter 'cancer centre'). 
Table 2 Geographical and socioeconomic environment influence on survival for patient with digestive tract cancer (models adjusted for age, gender, year of diagnosis and department)

\begin{tabular}{|c|c|c|c|c|c|c|c|c|c|c|c|c|c|c|c|c|}
\hline & & $\begin{array}{l}\text { esopha } \\
\qquad(N=)\end{array}$ & $\begin{array}{l}\text { geal ca } \\
7813)\end{array}$ & ancer & Stom & ich car & $r(N=$ & $1619)$ & Sm & $\begin{array}{l}\text { Ill inte } \\
(N=\end{array}$ & $\begin{array}{l}\text { tine ca } \\
\text { 1038) }\end{array}$ & incer & & olon ca & ancer ( & $=28010)$ \\
\hline & $\mathbf{R R}$ & $\begin{array}{c}\text { Confi } \\
\text { inte }\end{array}$ & $\begin{array}{l}\text { lence } \\
\text { val }^{\mathbf{a}}\end{array}$ & $P$-trend & $\mathbf{R R}$ & $\begin{array}{r}\text { Con } \\
\text { int }\end{array}$ & $\begin{array}{l}\text { lence } \\
\text { val }^{\mathbf{a}}\end{array}$ & $P$-trend & $\mathbf{R R}$ & $\begin{array}{c}\text { Conf } \\
\text { inte }\end{array}$ & $\begin{array}{l}\text { dence } \\
\text { val }^{\mathbf{a}}\end{array}$ & P-trend & $\mathbf{R R}$ & $\begin{array}{c}\text { Confic } \\
\text { inter }\end{array}$ & $\begin{array}{l}\text { dence } \\
\text { rval }^{\mathbf{a}}\end{array}$ & P-trend \\
\hline Distance to nearest & $t$ cance & er referer & ce care & centre $(\mathrm{km})$ & & & & & & & & & & & & \\
\hline$<10$ & 1.00 & & & 0.335 & 1.00 & & & 0.014 & 1.00 & & & 0.107 & 1.00 & & & 0.003 \\
\hline $10-30$ & 1.04 & 0.97 & 1.12 & & 1.00 & 0.93 & 1.06 & & 0.89 & 0.70 & 1.13 & & 1.10 & 1.04 & 1.15 & \\
\hline $70-90$ & 1.04 & 0.93 & 1.16 & & 1.09 & 1.00 & 1.20 & & 1.33 & 0.94 & 1.90 & & 1.09 & 1.01 & 1.17 & \\
\hline$>90$ & 1.06 & 0.93 & 1.22 & & 1.11 & 1.00 & 1.23 & & 0.94 & 0.63 & 1.39 & & 1.14 & 1.05 & 1.24 & \\
\hline Proportion who did & not col & mplete & econdan & y education & to age & $5(\%)$ & & & & & & & & & & \\
\hline$<14$ & 1.00 & & & 0.261 & 1.00 & & & 0.138 & 1.00 & & & 0.122 & 1.00 & & & 0.002 \\
\hline $14-19$ & 1.03 & 0.96 & 1.11 & & 1.03 & 0.97 & 1.10 & & 1.21 & 0.97 & 1.52 & & 1.08 & 1.03 & 1.13 & \\
\hline $19-23$ & 1.05 & 0.98 & 1.13 & & 1.01 & 0.95 & 1.08 & & 1.18 & 0.94 & 1.48 & & 1.08 & 1.03 & 1.13 & \\
\hline $13458-14997$ & 1.00 & 0.94 & 1.07 & & 0.97 & 0.92 & 1.03 & & 0.96 & 0.77 & 1.20 & & 0.97 & 0.92 & 1.01 & \\
\hline$|4997-167| \mid$ & 0.96 & 0.89 & 1.03 & & 0.96 & 0.90 & 1.02 & & 1.18 & 0.93 & 1.50 & & 0.99 & 0.94 & 1.04 & \\
\hline$>16711$ & 0.95 & 0.89 & 1.02 & & 0.97 & 0.93 & 1.01 & & 0.96 & 0.76 & 1.23 & & 0.92 & 0.88 & 0.97 & \\
\hline Unemployment rate & e (\%) & & & & & & & & & & & & & & & \\
\hline$<7.9$ & 1.00 & & & 0.538 & 1.00 & & & 0.591 & 1.00 & & & 0.547 & 1.00 & & & 0.865 \\
\hline $7.9-12$ & 0.96 & 0.90 & 1.03 & & 0.93 & 0.88 & 0.98 & & 0.91 & 0.74 & 1.13 & & 1.00 & 0.96 & 1.05 & \\
\hline $12-15$ & 0.99 & 0.92 & 1.06 & & 0.94 & 0.88 & 0.99 & & 1.03 & 0.83 & 1.27 & & 1.00 & 0.95 & 1.05 & \\
\hline$>15$ & 1.02 & 0.94 & 1.10 & & 0.98 & 0.92 & 1.05 & & 1.03 & 0.82 & 1.30 & & 1.00 & 0.94 & 1.05 & \\
\hline Proportion of house & es witho & out bath & or show & $\operatorname{er}(\%)$ & & & & & & & & & & & & \\
\hline$<1.1$ & 1.00 & & & 0.004 & 1.00 & & & 0.080 & 1.00 & & & 0.823 & 1.00 & & & 0.143 \\
\hline $1.1-1.7$ & 1.06 & 0.98 & 1.14 & & 1.02 & 0.96 & 1.08 & & 1.10 & 0.88 & 1.36 & & 1.06 & 1.01 & 1.11 & \\
\hline & & $\begin{array}{r}\text { Rectu } \\
(\mathbf{N}=\end{array}$ & $\begin{array}{l}n \text { canc } \\
18080)\end{array}$ & & & er canc & $(\mathbf{N}=$ & 197) & Gall bl & $\begin{array}{l}\text { idder a } \\
\text { incer ( }\end{array}$ & $\begin{array}{l}\text { nd bilia } \\
\mathbf{V}=\mathbf{2 8 9}\end{array}$ & Iry tract & Pan & creatic & cance & $(N=6018)$ \\
\hline & $\mathbf{R R}$ & $\begin{array}{c}\text { Confi } \\
\text { inte }\end{array}$ & $\begin{array}{l}\text { lence } \\
\text { val }^{\mathbf{a}}\end{array}$ & $P$-trend & $\mathbf{R R}$ & $\begin{array}{c}\text { Con } \\
\text { int }\end{array}$ & $\begin{array}{l}\text { lence } \\
\text { val }^{\mathbf{a}}\end{array}$ & $P$-trend & $\mathbf{R R}$ & $\begin{array}{c}\text { Conf } \\
\text { inte }\end{array}$ & $\begin{array}{l}\text { dence } \\
\text { val }^{\mathbf{a}}\end{array}$ & P-trend & $\mathbf{R R}$ & $\begin{array}{c}\text { Confic } \\
\text { inter }\end{array}$ & $\begin{array}{l}\text { dence } \\
\text { rval }^{\mathbf{a}}\end{array}$ & $P$-trend \\
\hline Distance to nearest & $t$ cance & er care $c$ & ntre $(k n$ & & & & & & & & & & & & & \\
\hline$<10$ & 1.00 & & & 0.024 & 1.00 & & & 0.629 & 1.00 & & & 0.529 & 1.00 & & & 0.246 \\
\hline $10-30$ & 1.09 & 1.03 & 1.15 & & 0.96 & 0.88 & 1.04 & & 0.95 & 0.84 & 1.07 & & 1.03 & 0.95 & 1.13 & \\
\hline $30-50$ & 1.08 & 1.02 & 1.14 & & 0.98 & 0.91 & 1.07 & & 1.02 & 0.90 & 1.15 & & 1.05 & 0.96 & 1.14 & \\
\hline $50-70$ & 1.12 & 1.05 & 1.19 & & 0.91 & 0.83 & 1.01 & & 1.02 & 0.88 & 1.19 & & 1.03 & 0.93 & 1.14 & \\
\hline $70-90$ & 1.04 & 0.96 & 1.13 & & 1.03 & 0.90 & 1.17 & & 0.98 & 0.82 & 1.17 & & 1.03 & 0.91 & 1.17 & \\
\hline$>90$ & 1.06 & 0.96 & 1.16 & & 1.01 & 0.87 & 1.17 & & 1.09 & 0.89 & 1.34 & & 1.11 & 0.96 & 1.29 & \\
\hline Proportion who did & not col & mplete & econdan & y educatio & to age & 5 (\%) & & & & & & & & & & \\
\hline$<14$ & 1.00 & & & 0.002 & 1.00 & & & 0.444 & 1.00 & & & 0.899 & 1.00 & & & 0.197 \\
\hline $14-19$ & 1.05 & 0.99 & 1.11 & & 0.95 & 0.87 & 1.03 & & 1.03 & 0.91 & 1.16 & & 1.04 & 0.96 & 1.13 & \\
\hline $19-23$ & 1.07 & 1.02 & 1.13 & & 0.94 & 0.87 & 1.02 & & 1.03 & 0.92 & 1.16 & & 1.07 & 0.99 & 1.16 & \\
\hline$>23$ & 1.09 & 1.03 & 1.15 & & 0.97 & 0.89 & 1.05 & & 0.99 & 0.88 & 1.12 & & 1.05 & 0.97 & 1.13 & \\
\hline Mean taxable incor & me (in & euros) & & & & & & & & & & & & & & \\
\hline$<13458$ & 1.00 & & & 0.132 & 1.00 & & & 0.637 & 1.00 & & & 0.991 & 1.00 & & & 0.167 \\
\hline $13458-14997$ & 0.97 & 0.92 & 1.02 & & 1.01 & 0.93 & 1.09 & & 1.03 & 0.91 & 1.16 & & 1.06 & 0.98 & 1.14 & \\
\hline$|4997-167| \mid$ & 0.96 & 0.91 & 1.02 & & 0.99 & 0.90 & 1.07 & & 1.00 & 0.88 & 1.13 & & 1.03 & 0.95 & 1.12 & \\
\hline$>16711$ & 0.96 & 0.90 & 1.01 & & 0.99 & 0.91 & 1.07 & & 0.99 & 0.87 & 1.12 & & 0.95 & 0.88 & 1.03 & \\
\hline
\end{tabular}




\begin{tabular}{|c|c|c|c|c|c|c|c|c|c|c|c|c|c|c|c|c|}
\hline & \multicolumn{4}{|c|}{$\begin{array}{l}\text { Rectum cancer } \\
(N=18080)\end{array}$} & \multicolumn{4}{|c|}{ Liver cancer $(N=5797)$} & \multicolumn{4}{|c|}{$\begin{array}{c}\text { Gall bladder and biliary tract } \\
\text { cancer }(N=2893)\end{array}$} & \multicolumn{4}{|c|}{ Pancreatic cancer $(N=6018)$} \\
\hline & \multicolumn{3}{|c|}{ RR $\begin{array}{c}\text { Confidence } \\
\text { interval }^{\mathrm{a}}\end{array}$} & \multirow[t]{2}{*}{ P-trend } & \multirow[t]{2}{*}{$\mathbf{R R}$} & \multicolumn{2}{|c|}{$\begin{array}{l}\text { Confidence } \\
\text { interval }^{\mathrm{a}}\end{array}$} & \multirow{3}{*}{$\begin{array}{c}\text { P-trend } \\
0.010\end{array}$} & \multirow{3}{*}{$\begin{array}{l}\text { RR } \\
1.00\end{array}$} & \multicolumn{2}{|c|}{$\begin{array}{l}\text { Confidence } \\
\text { interval }^{\mathrm{a}}\end{array}$} & \multirow{3}{*}{$\begin{array}{c}\text { P-trend } \\
0.744\end{array}$} & \multirow[t]{2}{*}{$\mathbf{R} \mathbf{R}$} & \multicolumn{2}{|c|}{$\begin{array}{l}\text { Confidence } \\
\text { interval }^{\mathbf{a}}\end{array}$} & \multirow[t]{2}{*}{ P-trend } \\
\hline Unemploym & (\%) & & & & & & & & & & & & & & & \\
\hline$<7.9$ & 1.00 & & & 0.990 & 1.00 & & & & & & & & 1.00 & & & 0.073 \\
\hline $7.9-12$ & 1.03 & 0.98 & 1.09 & & 1.02 & 0.94 & 1.10 & & 1.03 & 0.92 & 1.15 & & 1.06 & 0.99 & 1.14 & \\
\hline $12-15$ & 1.01 & 0.96 & 1.06 & & 1.09 & 1.01 & 1.18 & & 1.02 & 0.92 & 1.14 & & 1.05 & 0.95 & 1.16 & \\
\hline$>15$ & 1.01 & 0.95 & 1.07 & & 1.09 & 1.00 & 1.19 & & 1.02 & 0.90 & 1.16 & & 1.09 & 1.00 & 1.18 & \\
\hline \multicolumn{17}{|c|}{ Proportion of housing without bath or shower (\%) } \\
\hline$<1.1$ & 1.00 & & & 0.113 & 1.00 & & & 0.104 & 1.00 & & & 0.147 & 1.00 & & & 0.664 \\
\hline $1.1-1.7$ & 1.00 & 0.94 & 1.05 & & 1.01 & 0.93 & 1.09 & & 0.98 & 0.87 & 1.10 & & 1.02 & 0.94 & 1.10 & \\
\hline $1.7-2.7$ & 1.03 & 0.98 & 1.09 & & 1.02 & 0.94 & 1.10 & & 0.96 & 0.85 & 1.08 & & 1.00 & 0.92 & 1.08 & \\
\hline$>2.7$ & 1.04 & 0.98 & 1.10 & & 0.92 & 0.85 & 1.01 & & 0.91 & 0.81 & 1.04 & & 1.03 & 0.94 & I.I | & \\
\hline \multicolumn{17}{|c|}{ Proportion of manual workers (\%) } \\
\hline$<13$ & 1.00 & & & 0.009 & 1.00 & & & 0.723 & 1.00 & & & 0.625 & 1.00 & & & 0.032 \\
\hline $13-17$ & 1.07 & 1.01 & 1.13 & & 0.99 & 0.91 & 1.08 & & 0.97 & 0.86 & 1.09 & & 1.09 & 1.01 & 1.19 & \\
\hline$|7-2|$ & 1.10 & 1.04 & 1.16 & & 1.03 & 0.95 & 1.12 & & 0.96 & 0.86 & 1.08 & & 1.11 & 1.03 & 1.20 & \\
\hline$>21$ & 1.07 & 1.01 & 1.14 & & 0.97 & 0.89 & 1.06 & & 0.97 & 0.86 & 1.09 & & 1.10 & 1.00 & 1.19 & \\
\hline
\end{tabular}

${ }^{\mathrm{a}} 95 \%$ confidence interval. $\mathrm{RR}=$ relative risk.

\section{Oesophageal cancer}

Distance to the nearest cancer centre was not associated with survival. The proportion of housing without bath or shower was significantly associated with prognosis $(P$-trend $=0.004)$. In comparison with patients living in a Commune with less than $1.1 \%$ houses without bath or shower, patients living in a Commune with a high proportion of housing without bath or shower had poorer prognosis (relative risk $(\mathrm{RR})=1.08 \quad(1.00-1.16)$ and $\mathrm{RR}=1.12(1.04-1.20)$, respectively for $1.7-2.7$ and $>2.7 \%$ of housing without bath or shower).

\section{Stomach cancer}

Distance to nearest cancer centre was associated with prognosis $(P$-trend $=0.0014)$ even after adjustment for age, gender and department of residence, patients living far from a cancer centre having poorer prognosis than those living closer $(R R=1.09$ $(1.00-1.20)$ and $\mathrm{RR}=1.11(1.00-1.23)$, respectively, for $50-70$, and $>90 \mathrm{~km})$.

The association of prognosis with the proportion of housing without bath or shower was close to significant $(P=0.08)$, being significant when the department of residence was excluded from the analysis; those in a Commune with a high proportion of housing without bath or shower having poorer prognosis ( $P$-trend $<0.001$ ) (results not shown).

\section{Small intestine}

Although the prognosis of cancer did not decrease with the distance to nearest cancer centre, the prognosis of patients living $30-50 \mathrm{~km}$ from a cancer centre was significantly poorer than those living less than $10 \mathrm{~km}$ away $(\mathrm{RR}=1.48(1.18-1.85))$. An increasing proportion of manual workers was somewhat associated with poorer prognosis $(P$-trend $=0.072)$, becoming significant when the proportion of manual workers was used as a continuous variable $(P$-trend $=0.02)$ (results not shown).

\section{Colon cancer}

After adjustment for individual characteristics, patients living far from a cancer centre had poorer survival than those living closer $(\mathrm{RR}=1.10(1.04-1.16), 1.10(1.04-1.16)$ and $1.14(1.05-1.23)$, respectively, for distance of $10-30 \mathrm{~km}, 30-50 \mathrm{~km}$ and over $90 \mathrm{~km}$, compared to less than $10 \mathrm{~km}, P=0.003$ ).

Compared to patients living in a Commune with less than $14 \%$ of people who did not complete secondary education to age 15, patients living in a Commune with a greater proportion had a poorer survival $(P$-trend $=0.002)$. Patients living a Commune with low mean taxable income $(<13548$ euros) had poorer survival than those in a more affluent Commune $(\mathrm{RR}=0.92$ $(0.88-0.97)$ with mean taxable income $>16711$ euros) $(P$ trend $=0.002$ ).

\section{Rectum cancer}

Patients living far from a cancer centre had poorer prognosis than those living closer $(\mathrm{RR}=1.09(1.03-1.15), \mathrm{RR}=1.08(1.02-1.14)$ and $R R=1.12(1.05-1.19)$, respectively, for distances to nearest cancer centre of $10-30,30-50$ and $50-70 \mathrm{~km}$ compared with less than $10 \mathrm{~km}, P$-trend $=0.024)$. In comparison with patients living in a Commune with a low proportion of people who did not complete secondary education to age 15 , those living in a Commune with a higher proportion of people who did not complete secondary education to age 15 had a poorer survival $(R R=1.07(1.02-1.13)$ and $R R=1.09(1.03-1.15)$, respectively, for proportion of people who did not complete secondary education to age 15 of $19-23$ and $>23 \%$ ). In comparison with patients living in a Commune with less than $13 \%$ of manual workers, those living in a Commune with a higher proportion have poorer survival $(\mathrm{RR}=1.07(1.01-1.13), \mathrm{RR}=1.10(1.04-1.16)$ and $\mathrm{RR}=1.07$ (1.01-1.14), respectively for proportion of manual workers between 13 and 17,17 and 21 and $>21 \%$; $P$ trend $=0.009$ ). 
948

\section{Liver}

Distance to the nearest cancer centre was not associated with prognosis of liver cancer. Patients living in a Commune with a high unemployment rate had poorer survival than those in a lessdeprived Commune $(\mathrm{RR}=1.09(1.01-1.18)$ and $\mathrm{RR}=1.09$ (1.00$1.19)$, respectively, for unemployment rate $12-15 \%$ and above $15 \%$, compared with below $8 \%$; $P$-trend $=0.010$ ).

\section{Gall bladder and Biliary tract}

Neither socioeconomic variables nor distance to the nearest cancer centre were significantly associated with prognosis of gall bladder or biliary cancer.

\section{Pancreas}

Distance to the nearest cancer centre was not significantly associated with prognosis. Patients living in a Commune with a high proportion of manual workers had poorer prognosis than those living in a more affluent Commune $(P$-trend $=0.032)$. The association with unemployment rate was suggestive $(P$-trend $=0.073)$ and became significant $(P=0.034)$ when tested using a continuous variable.

\section{DISCUSSION}

These results support the hypothesis that socioeconomic and geographical environment influences prognosis of digestive cancer in France, as previously found in other European countries and in the USA (Woods et al, 2006). This influence appears to be significant for the most common cancers with better prognosis (colon, rectum), and to a lesser extent for cancers with poorer prognosis (oesophagus, stomach, liver and pancreas). No influence was found for gall bladder and biliary tract cancer.

Certain methodological aspects of our study are relevant. In the absence of individual-based social information, the surrogate of an aggregate (Commune level) social indicator was used. Moreover, no deprivation index is available in France, prompting a multidimensional approach to poverty (remote patient; education; income; working conditions and accommodation).

The level of geographical unit used in our study was the Commune. Communes are the smallest administrative unit in France but their population sizes vary widely. The National Institute for Statistics and Economic Studies (INSEE) has defined a smaller unit: 'Ilots regroupés d'indice statistique' (IRIS). Regional capital and other important Communes are divided into several IRIS and small Communes constitute one IRIS. Therefore, the use of IRIS increases the accuracy of socioeconomic variables in such studies (Woods et al, 2005). Unfortunately, the lack of information on patients' addresses prevented us from using the IRIS in our study. Socioeconomic inequalities highlighted in our study are likely to have been increased had we used the IRIS unit.

The use of relative survival, instead of crude survival, would have enabled us to adjust for comorbidity associated with age and gender, but to our knowledge, no multilevel relative survival model is available. As recently stressed (Auvinen and Karjalainen, 1997), relative survival tends to underestimate social inequalities in survival so we have preferred multilevel analysis rather than specific mortality.

The present study suffers from the lack of information on change in Census data during the study period. In fact, aggregate variables were collected in 1999 by the French Census and in 2003 for income tax purposes in an annual survey by the Direction Générale des Impôts, the tax department. The National Institute for Statistics and Economic Studies does not organise a Census each year. Furthermore, since multiple comparisons were made (six factors were tested for each of the eight cancers), some tests (two or three) may be significant by chance.

Nevertheless, our results accord with previous studies that stressed the appreciable gap between the most deprived and the most affluent in survival (Woods et al, 2006). At least in England and Wales, this was more widespread in the 1990s than previously (Coleman et al, 2004). In France, two studies, based on small samples, demonstrated that Communes with a high proportion of dwellings without bath or shower were negatively correlated with cancer survival (Monnet et al, 1993) and that farmers of both sexes and unemployed men had poorer survival than other socioeconomic categories (Desoubeaux et al, 1997). The frequent association of this housing measure suggested that it was a relevant socioeconomic indicator.

For cancers with good prognosis, in our study, the influence of socioeconomic aggregate variables on survival were similar to those in a Norwegian population-based study also using multilevel survival (discrete-time hazard regression) (Kravdal, 2006). In the Norwegian study, education variables (at individual and community level) were the most relevant socioeconomic indicators.

In our study, unlike the Norwegian study (Kravdal, 2006), road distance between cancer centres and the Commune of residence is a predictor of cancer survival for almost half of the cancer sites. This contradiction between the two studies may be partially explained by the adjustment for cancer stage at diagnosis in the Norwegian study. Lack of information on stage at diagnosis in our study restricts the interpretation of our results. Cancer stage at diagnosis is often more advanced in deprived people (Ionescu et al, 1998; Ciconne et al, 2000), although one recent study (Brewster et al, 2001) failed to find this for colorectal cancer using Carstairs deprivation categories. The explanation of social inequalities in cancer survival by the difference in stage at diagnosis is attractive as a consequence of the importance of stage at diagnosis as a prognostic factor. Nevertheless, as underlined by a recent review (Woods et al, 2006), stage at diagnosis does not entirely account for the gap in cancer survival between the most deprived and the most affluent.

Although geographic and socioeconomic effects on prognosis are modest compared to clinical prognostic factors such as histology or stage at diagnosis, they warrant consideration as potential survival predictors in digestive tract cancer. Few such studies have been carried out, partly due to the lack of individual-based information. Our study implies that the French health-care system, which theoretically provides free access to care to all patients, with extensive hospital services throughout the country, does not prevent social inequalities in cancer management.

\section{ACKNOWLEDGEMENTS}

This study received the financial support of the 'Fondation de France'. French census data were provided thanks to LASMAS ('longitudinal institute'). We thank all of the contributors to registry data, that is, general practitioners, pathologists, specialists, belonging to private or public health systems.

\section{REFERENCES}

Auvinen A, Karjalainen S (1997) Possible explanations for social class differences in cancer patient survival. In Social Inequalities and Cancer
Kogenivas M, Pearce N, Susser M, Boffetta P (eds) pp 377-397. Lyon: IARC Scientific Publications 
Berrino F, Capocaccia R, Coleman MP, Estève J, Gatta G, Hakulinen T, Micheli A, Sant M, Verdecchia A (2003) Survival of cancer patients in Europe: the EUROCARE-3 Study. Ann Oncol 14(S5): 62-118

Brewster D, Thomson C, Hole D, Black R, Stroner P, Gillis C, on behalf of the Scottish Cancer Therapy Network (2001) Relation between socioeconomic status and tumour stage in patient with breast, colorectal, ovarian and lung cancer: result from four national population based studies. BMJ 322: $830-831$

Ciccolallo L, Capocaccia R, Coleman MP, Berrino F, Coebergh JWW, Damhuis RAM, Faivre J, Martinez-Garcia C, Moller H, Ponz de Leon M, Launoy G, Raverdy N, Williams EMI, Gatta G (2005) Survival differences between European and US patient with colorectal cancer: role of stage at diagnosis and surgery. GUT 54: $268-273$

Ciconne G, Prastaro C, Ivaldi C, Giacometti R, Vineis P (2000) Access to hospital care, clinical stage and survival from colorectal cancer according to socio-economic status. Ann Oncol 11: $1201-1204$

Coleman MP, Rachet B, Woods LM, Mitry E, Riga M, Cooper N, Quinn MJ, Brenner H, Esteve J (2004) Trends and socioeconomic inequalities in cancer survival in England and Wales up to 2001. Br J Cancer 90: 1367-1373

Dejardin O, Bouvier A M, Hebert C, Velten M, Buemi A, Delafosse P, Maarouf N, Boutreux S, Launoy G (2005) Social and geographical disparities in access to reference care site for patients with colorectal cancer in France. Br J Cancer 92(10): $1842-1845$

Desoubeaux N, Herbert C, Launoy G, Maurel J, Gignoux M (1997) Social environment and prognosis of colorectal cancer patients: a French population-based study. Int J Cancer 73: 317-322

Goldstein H (1995) Multilevel Statistical Model, 1st edn. London: Arnold

Ionescu MV, Carey F, Tait IS Steele RJC (1998) Socioeconomic status and stage at presentation of colorectal cancer. Lancet 352: 1439

Kee F, Wilson RH, Harper C, Patterson CC, McCallion K, Houston RF, Moorehead RJ, Sloan JM, Rowlands BJ (1999) Influence of hospital and clinican workload on survival from colorectal cancer: cohort study. BMJ 318: $1381-1386$

Kravdal Ø (2006) Does place matter for cancer survival in Norway? A multilevel analysis of the importance of hospital affiliation and municipality socio-economic resources. Health Place 12: 527-537

Launoy G, Le Coutour X, Gignoux M, Pottier D, Dugleux G (1992) Influence of rural environment on diagnosis, treatment, and prognosis of colorectal cancer. J Epidemiol Commun Health 46: 365-367

Monnet E, Boutron MC, Faivre J, Milan C (1993) Influence of socioeconomic status on prognosis of colorectal cancer. A population-based study in Côte d'Or. France. Cancer 72: 1165-1170

Parkin DM, Whelan SL, Ferlay J, Teppo L, Thomas DB (2002) Cancer incidence in five continents, Volume VIII. Lyon, France: IARC Scientific publication

Platell C, Lim D, Tajudeen N, Tan JL, Wong K (2003) Does surgical subspecialization influence survival in patients with colorectal cancer? World J Gastroenterol 9(5): 61 -964

Remontet L, Estève J, Bouvier AM, Grosclaude P, Launoy G, Menegoz F, Exbrayat C, Tretare B, Carli PM, Guizard AV, Troussard X, Bercelli P, Colonna M, Halna JM, Hedelin G, Mace-Lesec'h J, Peng J, Buemi A, Velten M, Jougla E, Avreux P, Le Bodic L, Michel E, Sauvage M, Schvartz C, Faivre C (2003) Cancer incidence and mortality in France over the period 1978-2000. Rev Epidemiol Sante Publique 51: 3-30

Shrag D, Cramer L, Bach P, Cohen A, Warren J, Begg C (2000) Influence of hospital procedure volume on outcome following surgery for colon cancer. Lancet 284(23): 3028-3035

Woods LM, Rachet B, Colman MP (2005) Choice of geographic unit influences socioeconomic inequalities in breast cancer survival. $\mathrm{Br} J$ Cancer 92(7): 1279-1282

Woods LM, Rachet B, Coleman MP (2006) Origins of socio-economic inequalities in cancer survival: a review. Ann Oncol 17(1): 5-19 